\title{
FATIGUE INFRACTION OF THE MIDDLE OF THE TIBIA IN BALLET DANCERS
}

\author{
H. JACKSON BURROWS, LONDON, ENGLAND \\ From the Orthopaedic Department, St Bartholomew's Hospital, \\ and the Institute of Orthopaedics, Royal National Orthopaedic Hospital
}

In six years we have encountered an unusual defect of the shin in four ballet dancers and have carried out biopsy in two. A fifth dancer possibly had the same defect before a complete fracture of the tibia from muscle action. The chief symptom has been localised pain on leaping. A tender swelling has been found at about the middle of the tibial crest, where radiography has revealed a horizontal fissure with adjacent hyperostosis.

\section{CLINICAL MATERIAL}

Case 1-Defect of left tibia. Biopsy. A male ballet dancer aged twenty-three began to suffer a stab of pain in the middle of the front of his left shin when landing on this leg from leaps. A few days later while pulling on his socks he chanced upon a small tender hard lump at about the middle of the crest of his tibia. He did not limp, and he paid no attention at first, but the lump became larger and more tender.

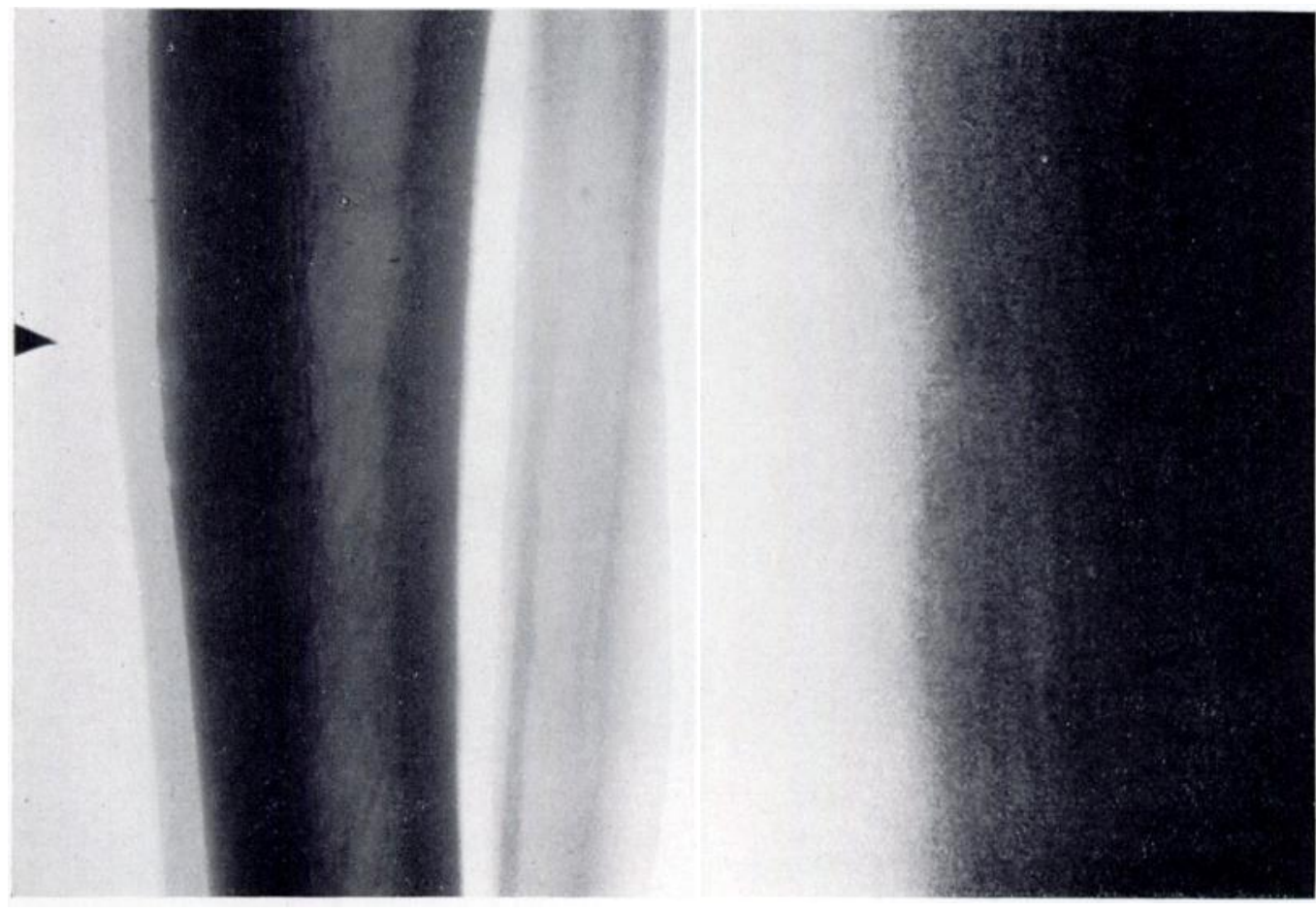

FIG. 1

Case 1-Radiograph a few days after onset of pain. (Right-hand radiograph, $\times 2$.)

Six weeks before he had attended elsewhere for an inversion sprain of the right ankle, which had since recovered almost fully.

On examination, palpable irregularity was confirmed at the site mentioned-but without tenderness on pressure or percussion, and without pain on movement except jumping.

Radiographs (Fig. 1), taken by Dr Campbell Golding, in various projections and with a marker over

VOL. 38 B, NO. 1, FEBRUARY 1956 


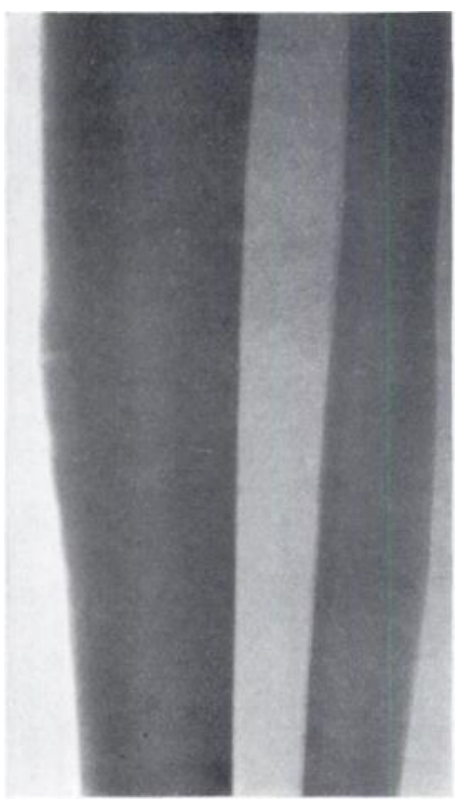

FIG. 2
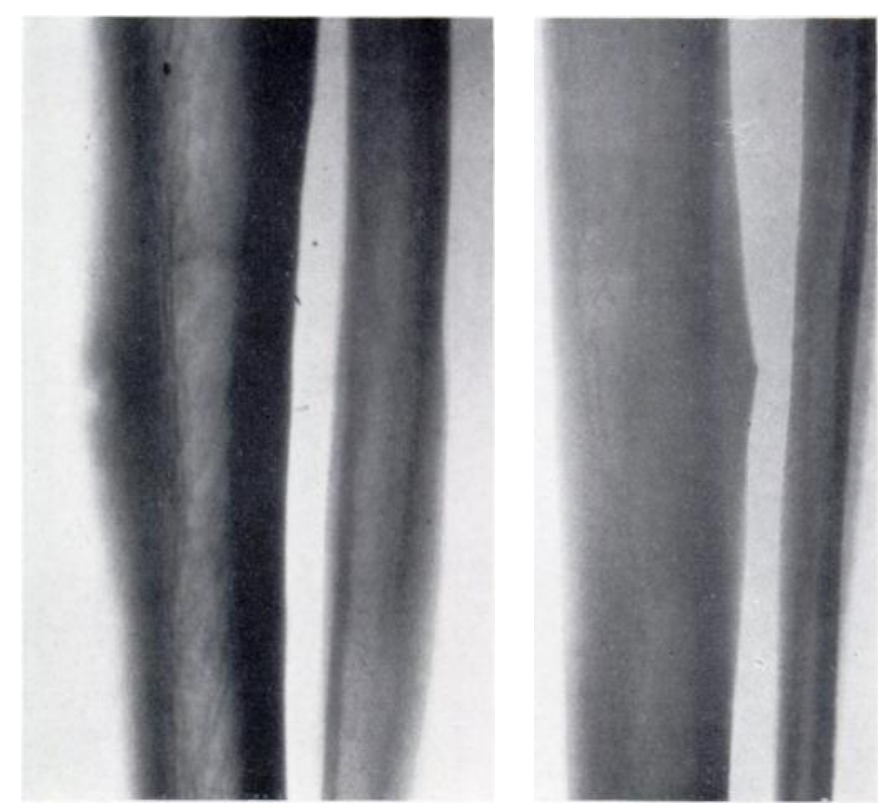

Fig. 3

Case 1-At five months and ten months, the radiographs show progressive hyperostosis of the front of the tibia with a clear intersection.

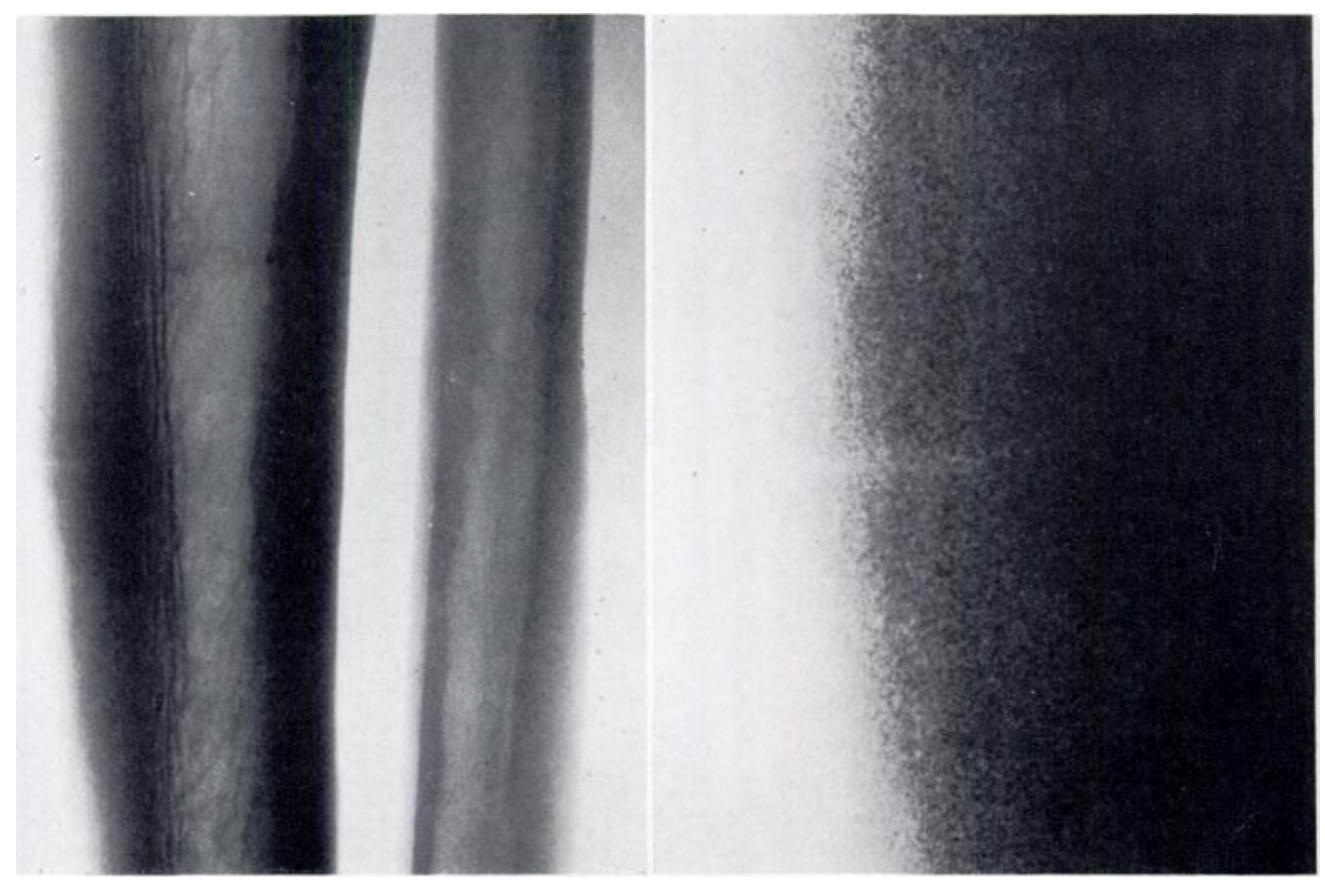

FIG. 4

Case 1-Six years and eight months after the onset, a defect was still evident although symptomless. (Right-hand radiograph, $\times 4$.)

THE JOURNAL OF BONE AND JOINT SURGERY 
the slight prominence, showed very slight irregularity here with a just perceptible underlying linear rarefaction running into the bone for 3 millimetres. The tibia was not measurably thickened. The Wassermann and Kahn reactions were negative.

During the next five months the patient carried on normally, but the pain steadily increased and the hard swelling of the front of the tibia gradually enlarged. It was still not tender, but the overlying skin, otherwise normal, was slightly hot. Pain was provoked by walking or dancing and relieved by rest. The radiographs now (Fig. 2), and five months later still (Fig. 3), showed a progressive increase in the fissure and the hyperostosis.

Biopsy-Fifteen months after the onset a block of bone was removed. This included the fissure, into which the periosteum seemed to sink. The rest of the hyperostosis was removed; it appeared whiter than the surrounding bone and was very hard, tending to flake beneath the osteotome.

Histology (Dr H. A. Sissons)-The cleft contained only a little fibrinous débris and fibrous tissue, without callus. The adjacent bone was normal except for some enlargement of the central vascular canals of its Haversian systems.

Progress after biopsy-The patient resumed ballet exercises four weeks after operation and full dancing at six weeks. A subsequent fracture of the base of the right fifth metatarsal bone from a supination injury healed normally.

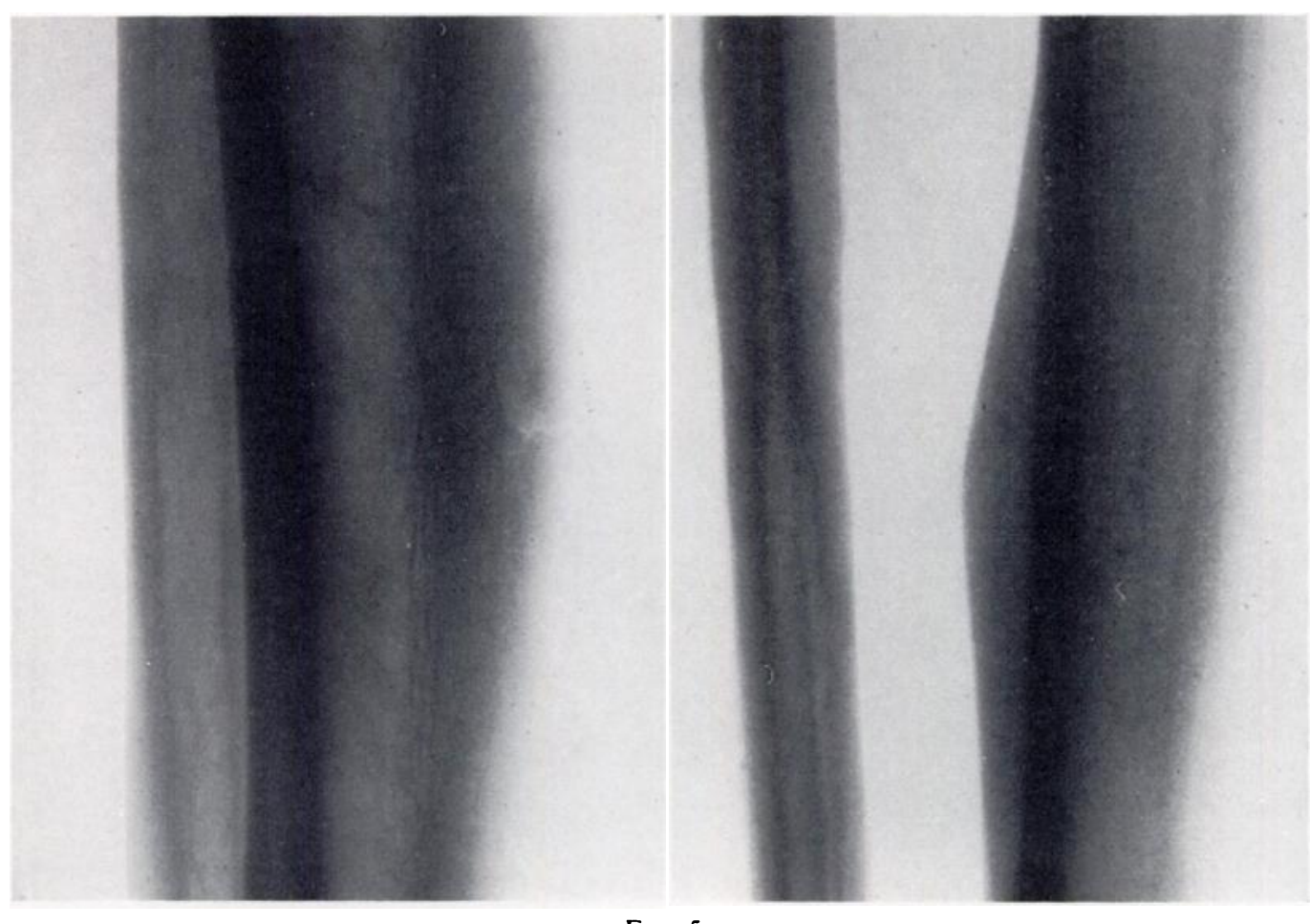

Fig. 5

Case 2-Mid-tibial crest when first radiographed, twenty months after onset; cortical thickening and intersection.

Six years and eight months after the onset (five years and five months after the biopsy) he was still at full work having had no further trouble whatever with the leg, which was normal on examination except for the operation scar. A radiograph still showed the defect, but faintly (Fig. 4). Further blood investigations were normal (serum calcium 9.2 milligrams per cent; serum alkaline phosphatase 5.8 King-Armstrong units) except for a slightly high serum inorganic phosphate content of 4.0 milligrams per cent.

Case 2-Defect of right tibia. (Presumed old fatigue fracture of second right metatarsal bone.) Biopsy. A male ballet dancer aged twenty-six was kicked on the right shin twenty months before, and had a further blow in the same place a few days later. After ten days' rest the pain disappeared and he resumed work. When jumping he began to notice gradually increasing local mid-tibial pain both on taking off and on landing. There was no pain with any other activity. Seven months later

VOL. 38 B, NO. 1, FEBRUARY 1956 

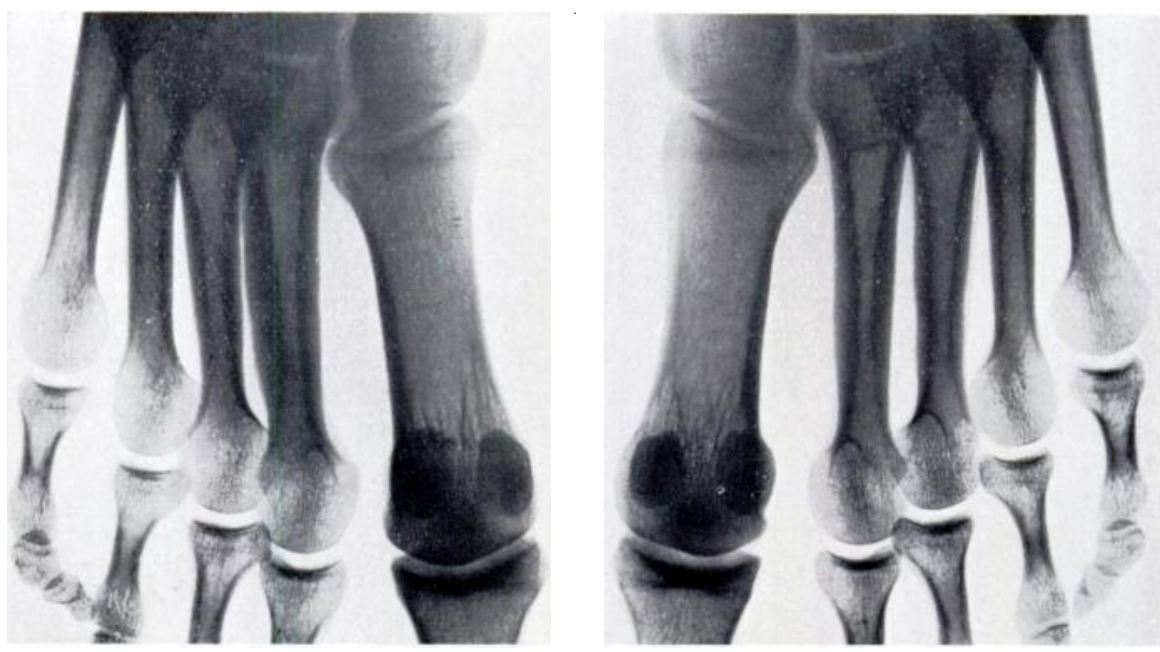

FIG. 6

Case 2-Lateral cortical thickening of second right metatarsal bone, possibly representing old fatigue fracture.

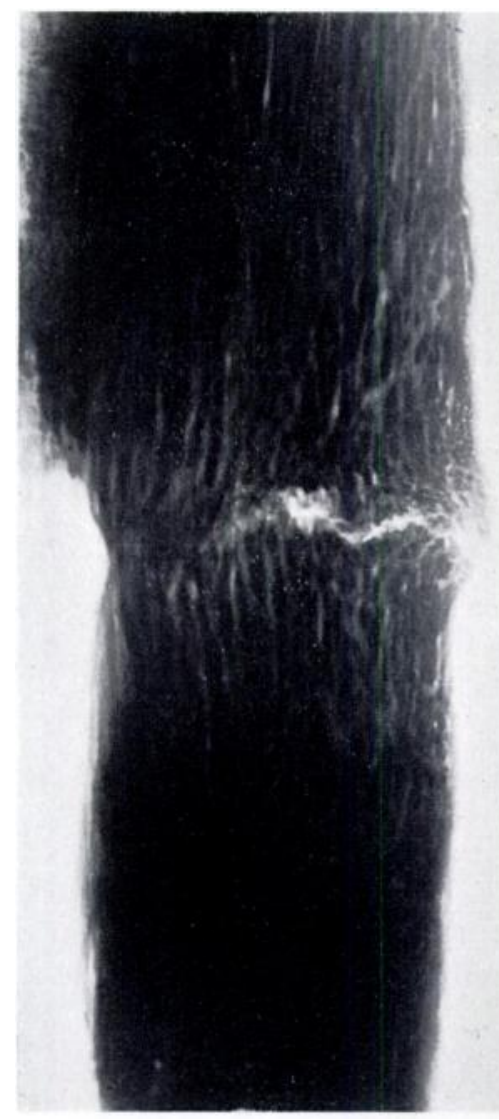

FIG. 7

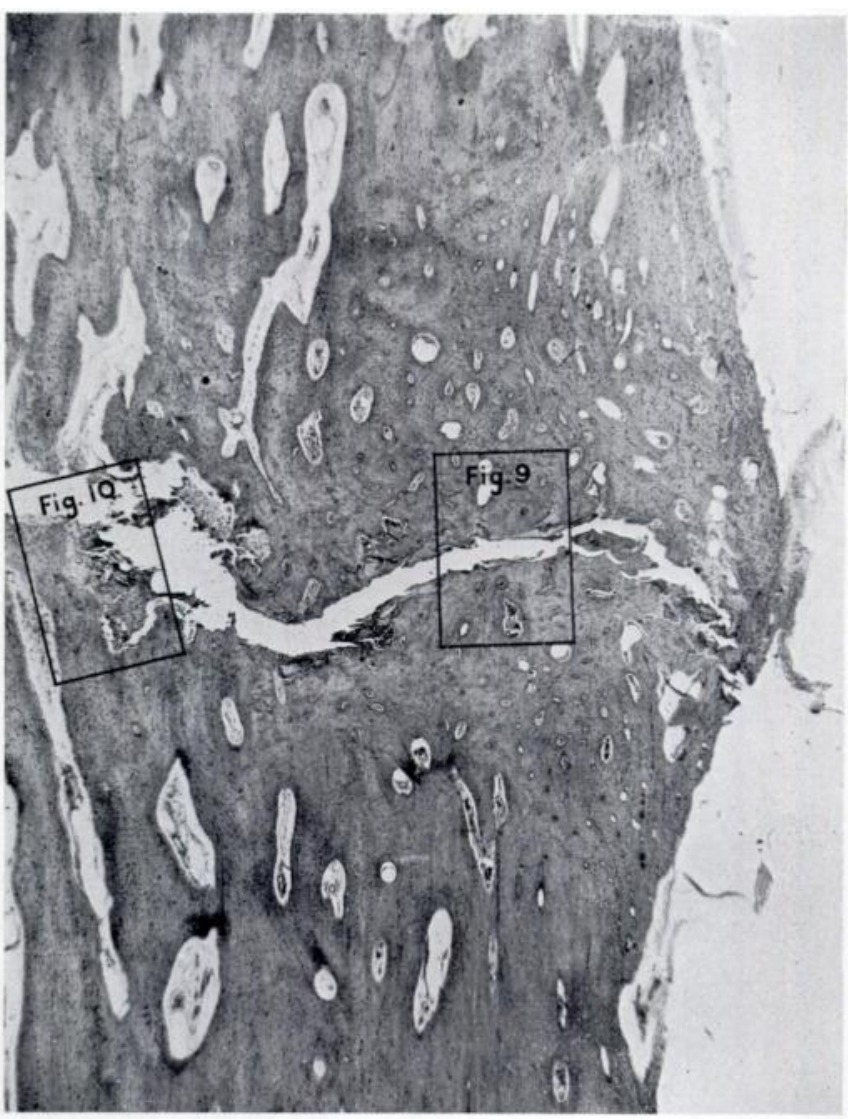

FIG. 8

Case 2. Figure 7-Radiomicrograph of biopsy specimen including the infraction; the periosteal surface is to the right. $(\times 4$.) Figure 8-Low-power photomicrograph of bone adjacent to the fracture defect. The periosteal surface of the bone is to the right. Deep to this, and traversed by the defect, is an area of newly formed bone tissue showing numerous small vascular channels. The rest of the bone in the field is compact cortical bone showing considerable enlargement of the vascular spaces of its Haversian systems. $(\times 16$. 


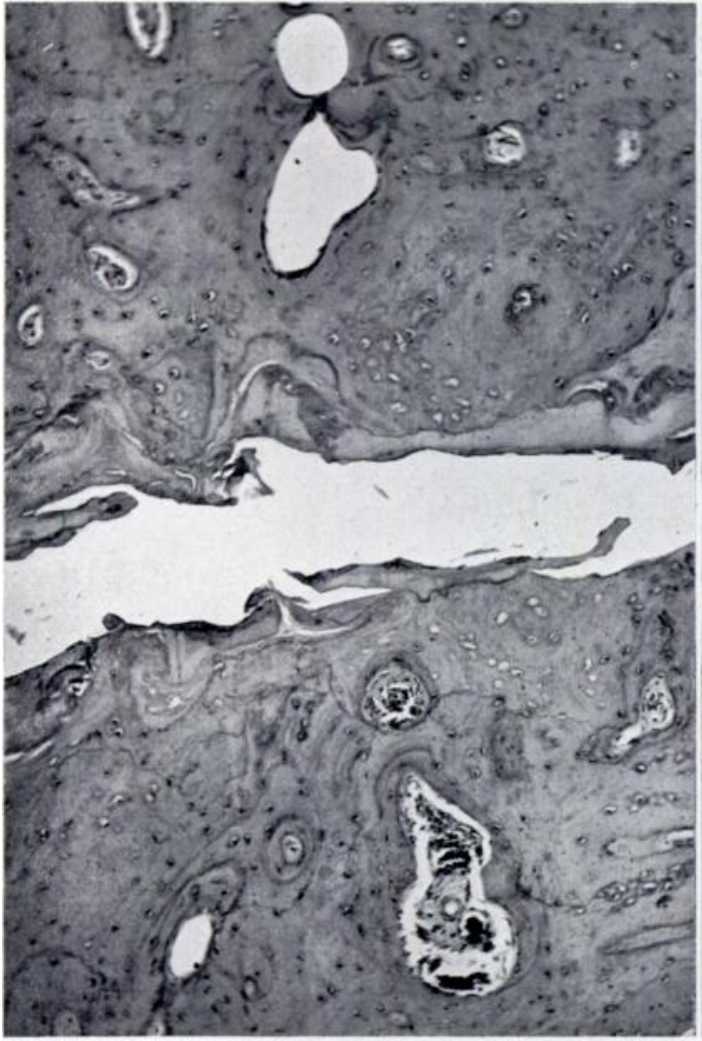

FIG. 9

Case 2. Figure 9-Histological structure of newly formed subperiosteal bone. The surface of the defect consists of normally calcified bone, partly covered by a layer of hyaline fibrinous material. The adjacent bone shows occasional empty lacunae. No excess osteoid tissue is present. $(\times 90$. $)$ Figure $10-$ An area where the surface of the cortical bone adjacent to the defect shows a small area of vascular granulation tissue containing a few necrotic bone fragments. $(\times 90$.

FIG. 11

An area of the deeper cortical bone adjacent to the defect. The vascular spaces of the Haversian systems are greatly enlarged. The bone immediately adjacent to the defect shows occasional empty lacunae, but is not otherwise abnormal. ( $\times 90$.) (Dr H. A. Sissons.)

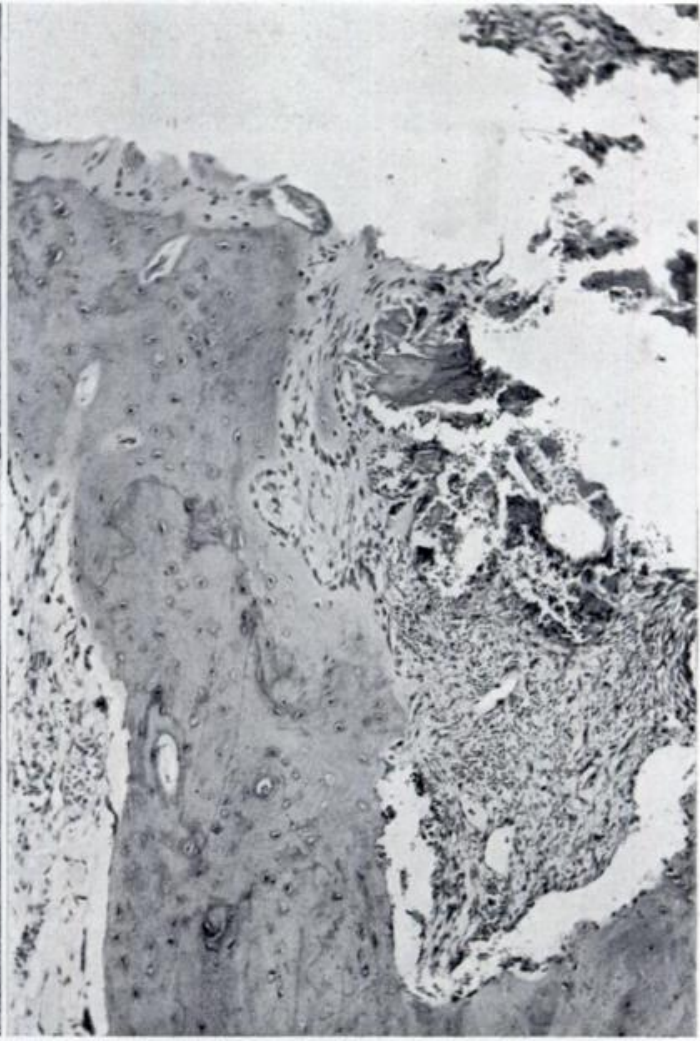

Fig. 10

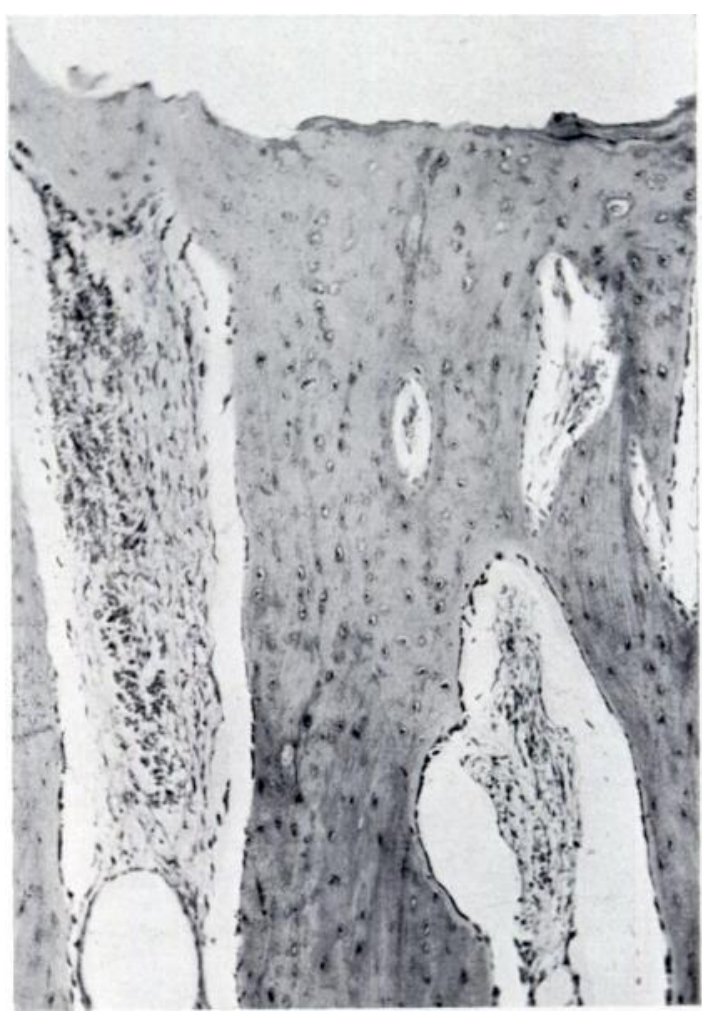

Fig. 11

VOL. 38 B, NO. 1, FEBRUARY 1956 
his doctor in Canada drew attention to a hard, tender ridge. He had radiographs taken, which were said to show a tibial fracture, and carried out a local operation. The patient resumed work after two months; but in the last eight months the pain was worse. Five weeks' rest from dancing failed to bring relief. He had no limp.

On examination, the only abnormal physical sign, except the scar of a presumed biopsy, was slight localised tenderness on strong pressure over the middle of the right tibial crest.

Radiographs showed at this point cortical thickening, half-transected by a horizontal crack (Fig. 5). No lesion was found elsewhere in the skeleton, except thickening of the lateral cortex of the second right metatarsal bone (Fig. 6).

Blood investigations were all normal-Hb. 14.8 grammes per 100 millilitres. W.B.C. 6,500 per cubic millimetre (P.4,290, L.2,015, E. 195, B. 0, M. 0). W.R. and Kahn tests negative. E.S.R. 5 millimetres 1 hour (Westergren). Serum calcium 10.6 milligrams per 100 millilitres. Serum inorganic phosphate 3.2 milligrams per 100 millilitres. Serum alkaline phosphatase 6 King-Armstrong units.

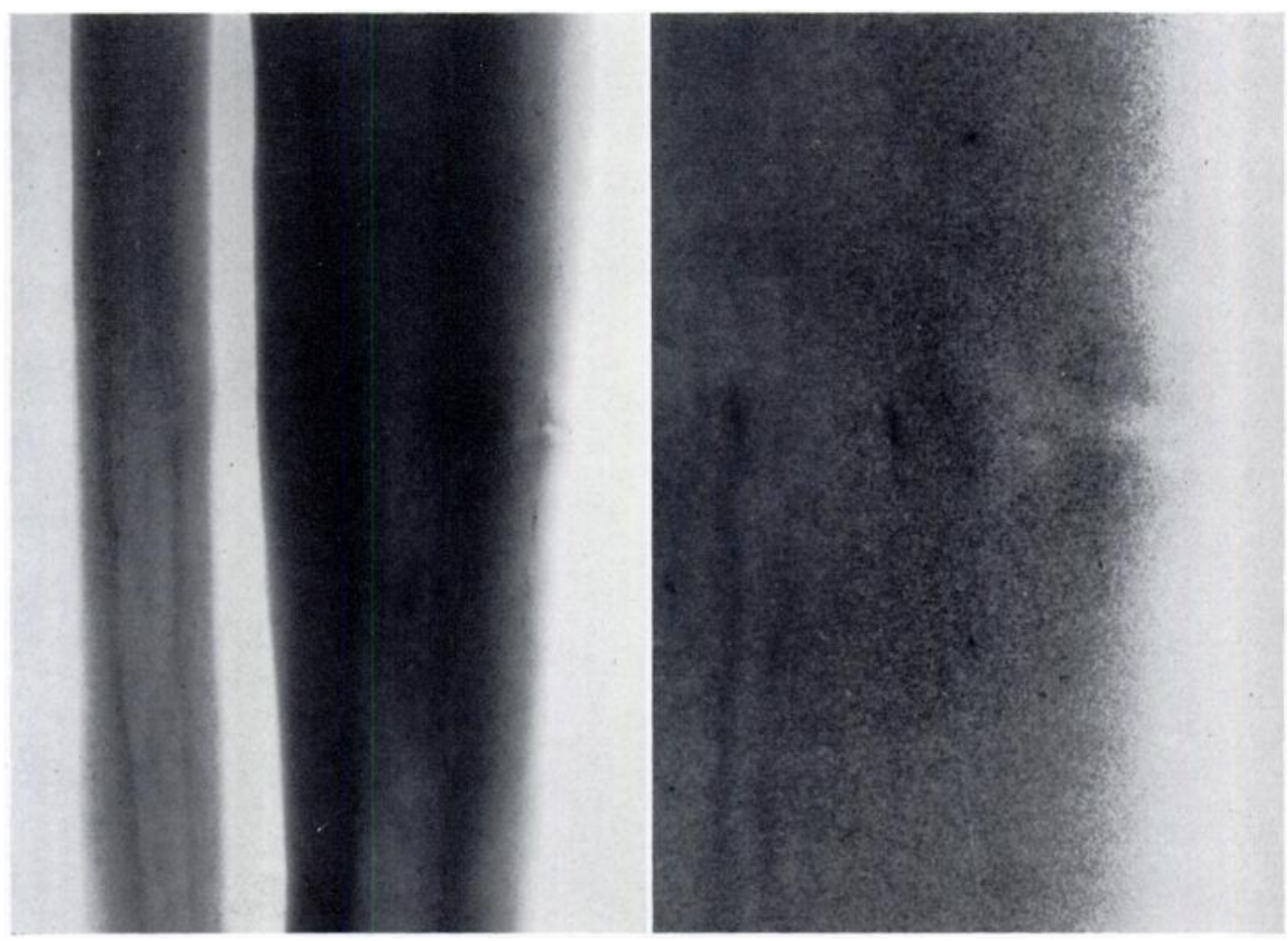

FIG. 12

Case 2-Three years and nine months after the onset, a defect is still visible. (Right-hand radiograph, 4 .)

Biopsy was performed twenty-two months after the onset. The locally thickened and sclerotic area of tibia was removed, together with a minute red horizontal fissure just discernible on the crest.

Histology (Dr H. A. Sissons) (Figs. 7 to 11)-The cleft was occupied by fibrinous débris and a small amount of vascular granulation tissue, without callus. On either side of it superficially there was some subperiosteal new bone, and more deeply the adjacent cortical bone showed rarefaction from enlargement of the Haversian canals, which contributed to the transradiancy of the defect. The remaining bone was normal.

Progress after biopsy-Despite some initial muscle stiffness and the formation of considerable subperiosteal radiating new bone, the patient made good progress and returned to full work. Now forty-five months after the onset (twenty-three months after the biopsy) he still has a little pain on taking off and on landing if he goes hard at a leap, so that he has "cut down on them a little "; nobody notices, and the slight trouble is becoming no worse. No tenderness or swelling has returned. A fresh radiograph (Fig. 12) still shows a small defect; the anterior tibial cortex is thinner than in the opposite leg, but the posterior cortex is thickened. 


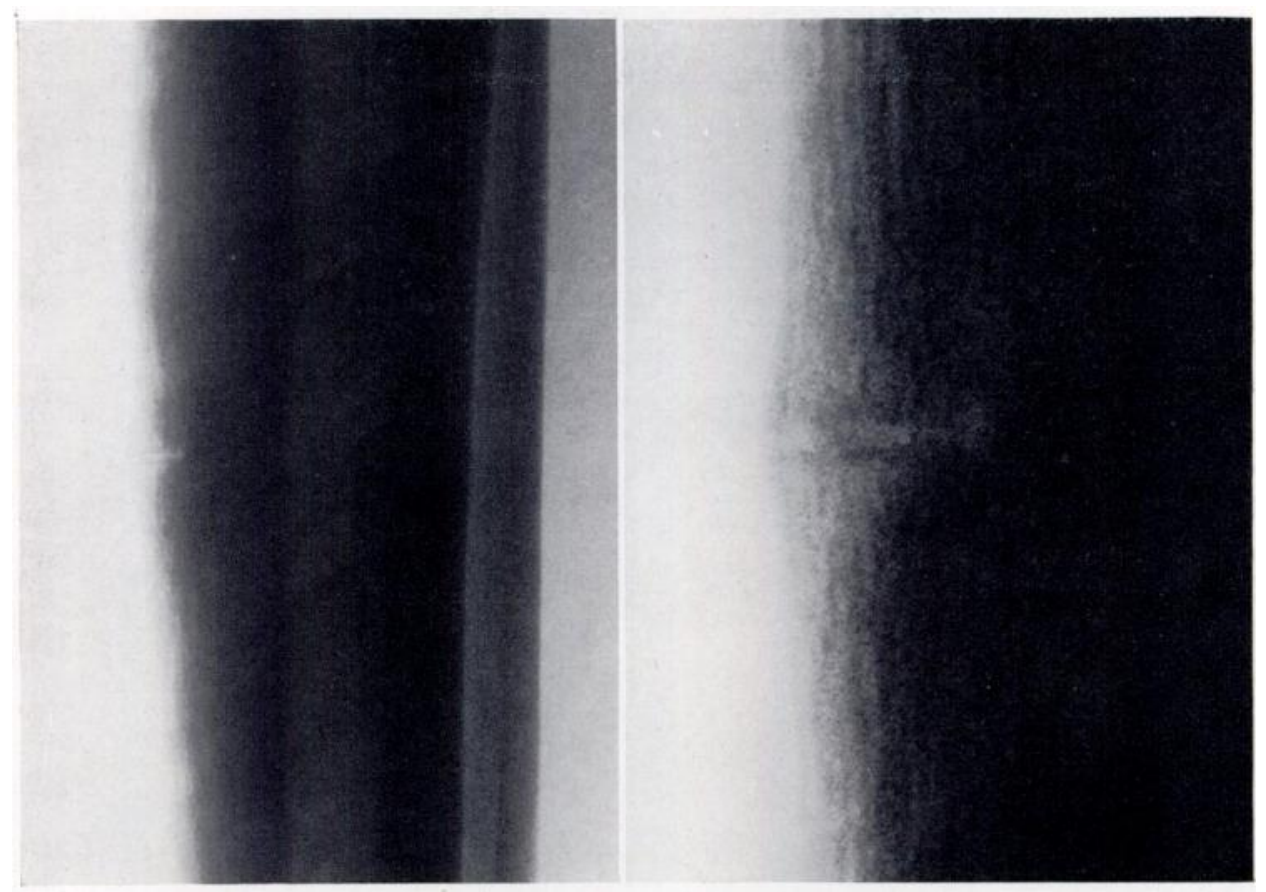

Fig. 13

Case 3-First radiograph, eight to ten weeks after onset of pain. (Right-hand radiograph, $\times 4$.)

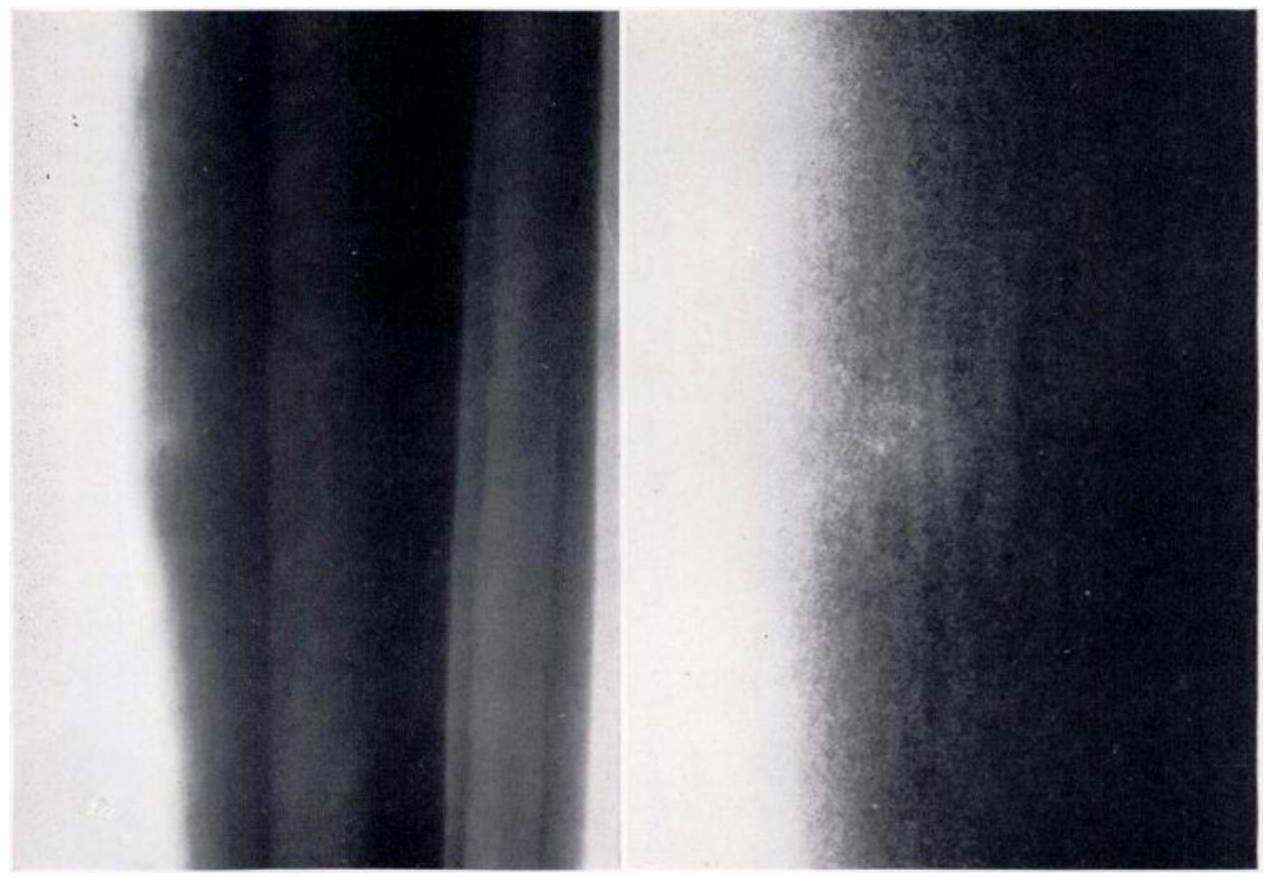

Fig. 14

Case 3-Thirteen weeks later. (Right-hand radiograph, $\times 4$.)

VOL. 38 B, NO. 1, FEBRUARY 1956 
Case 3-Defect of left tibia. More recent case. A male ballet dancer aged twenty-one had noticed, eight to ten weeks before, the gradual onset of diffuse aching in the front of the left shin, especially on forced dorsiflexion or plantar flexion of the ankle, or on negotiating stairs-going up more than down. There was no pain except when weight was taken. For four weeks he had been unable to jump on his left leg, and there was localised tenderness of the middle of the front of the shin.

Examination revealed a tender lccalised swelling of the middle of the tibial crest and slight tenderness of the corresponding subcutaneous surface. Radiography showed a defect in the thickened tibial crest (Fig. 13).

With rest from work the swelling diminished and a groove became palpable across it. Radiographs showed improvement. After only thirteen weeks the intersection appeared to have been replaced by a faint, buried, rounded area of rarefaction slightly reminiscent of osteoid osteoma (Fig. 14). He then resumed work-gradually, intermittently, and with pain on jumping. Now, thirteen months after the onset, he is at full work on tour abroad with the first company, and reports, " My leg is giving me no trouble at all even when I do a lot of jumping, although at times it is slightly painful to touch at the spot where the fracture occurred."

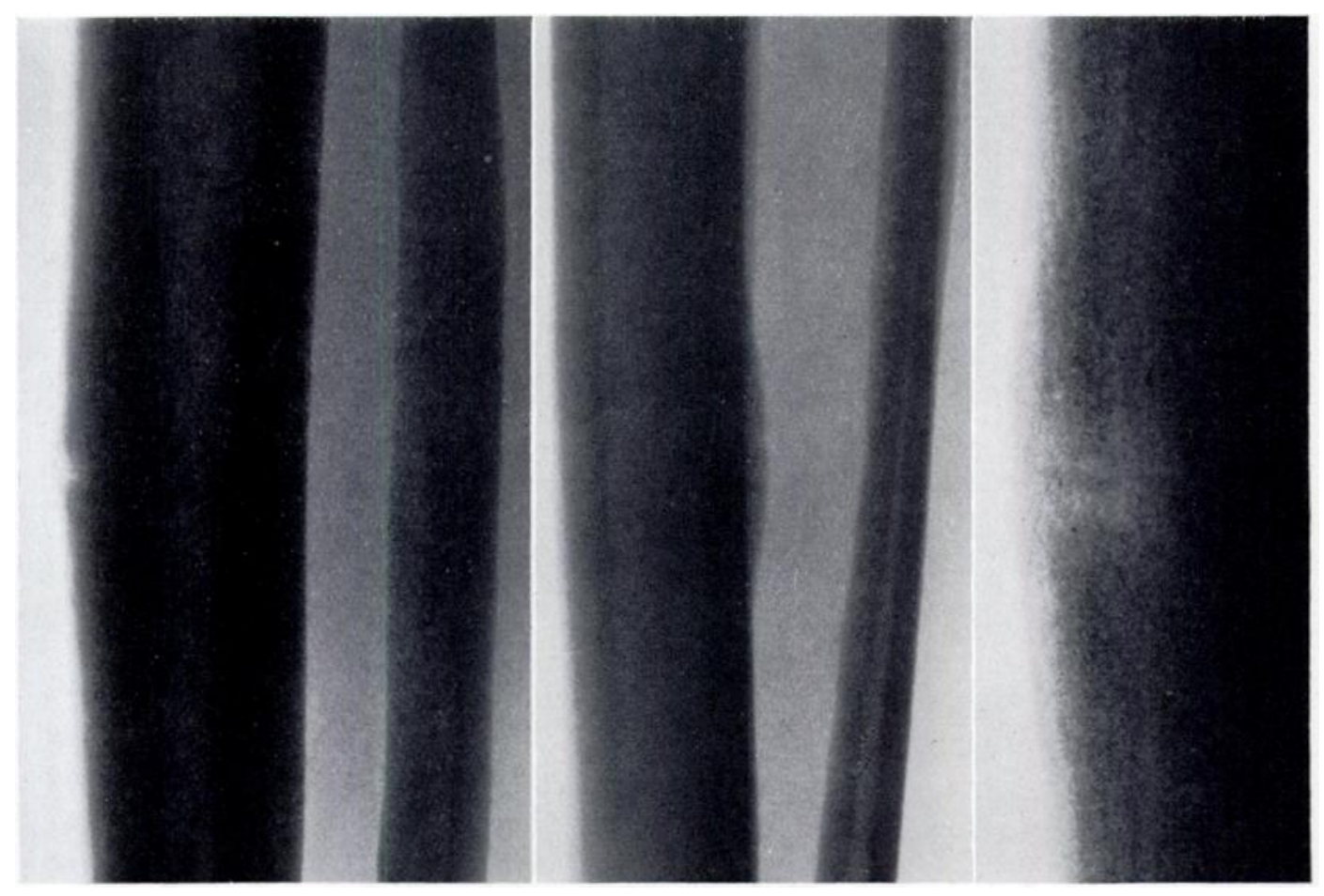

Fig. 15

Case 4-Our only case in a woman. (Right-hand radiograph, $\times 4$.)

Case 4-Defect of the left tibia. Only case in a danseuse. With very prolonged and arduous dancing in the ballet Carmen, a French ballerina in her twenties suffered gradually increasing pain at the middle of her shin, which presented a tender mid-tibial swelling. She could not recollect any injury. Radiographs showed a linear defect and some thickening of the left tibial crest (Fig. 15); the right tibia was normal. The pain and swelling increased, and after a year the swelling was excised in France. No further details are obtainable except that she returned to full dancing.

Case 5 is of speculative interest, but is included as a possible example of a serious complication, spontaneous fracture, already reported in fatigue infraction of the tibia (Hartley $1942,1943)$. The patient noticed a tender swelling at the middle of the tibial crest; this proved a site of weakness, because a few days later the tibia broke here with muscle action. The initial tender lump may have indicated the condition found in Cases 1 to 4 . 
Case 5-Complication of presumed defect of left tibia. Acute fracture from muscle action. This ballet dancer aged twenty had suddenly begun to notice left mid-tibial pain whenever he took off in a jump; a week later this complaint had drawn his attention to a slightly tender hard lump half an inch in diameter on his left shin bone. Thereupon radiographs had been taken of the ankle and lower six inches of the tibia; they omitted the site of complaint, and were pronounced normal. There was no limp. About seven days later, just as he leapt, he felt and heard a "colossal crack" in the same place. Sure that he had broken the leg, he landed on the other one and did not try to walk. Radiographs showed a comminuted fracture of the middle of the tibia (Fig. 16).

A satisfactory position was maintained in plaster-of-Paris. There was clinical and early radiological evidence of union at seventeen weeks. Partial weight bearing out of plaster was then allowed with crutches and sticks; but twelve days later he stepped smartly out of the way of a bowl

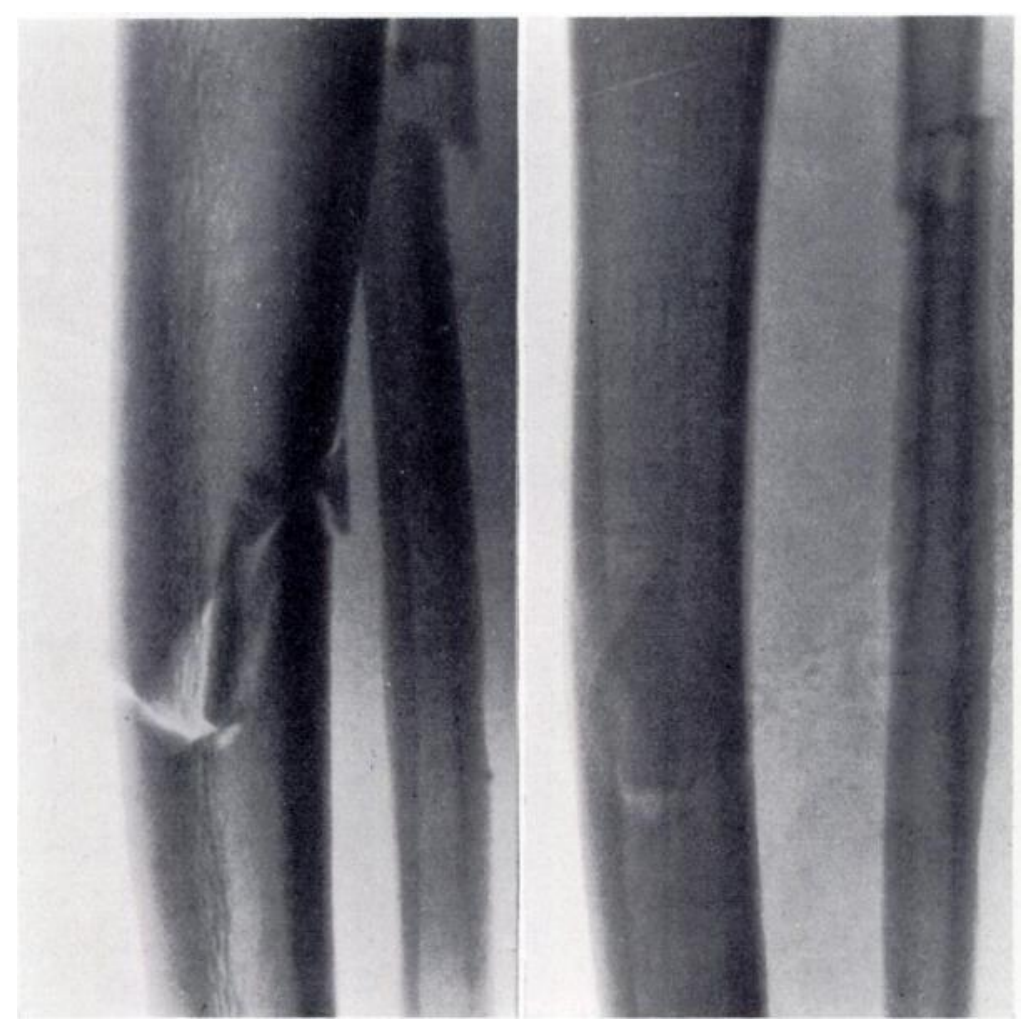

Fig. 16

Case 5-Comminuted fracture of mid-tibia and of fibula from indirect violence after symptoms suggesting the defect here described.

at a rehabilitation centre, felt a crack in the left leg, and was unable to stand on it. Clinical and radiological examination confirmed refracture. With five months' plaster-of-Paris support the fracture united posteriorly; a gap remained in front for a further two months.

Fourteen months after the original fracture there were firm consolidation and full joint movement. He had become a stage manager, but still took part in dancing which, three months later, still caused an occasional ache and an occasional "twinge" at the site of fracture when he took weight on his left leg alone. The girth of the left calf was half an inch less than the right.

Radiographs remained satisfactory.

Pathological investigations gave normal results (serum calcium $9 \cdot 5$ milligrams per 100 millilitres; serum alkaline phosphatase 7-9 King-Armstrong units) except perhaps for a rather high serum inorganic phosphate content ( $4 \cdot 1$ milligrams per 100 millilitres).

VOL. 38 B, NO. 1, FEBRUARY 1956 


\section{DISCUSSION}

THE CHARACTERISTICS OF THE SYNDROME

The patients were young, healthy ballet dancers. Though women greatly outnumber men in the profession, only one of our patients was a woman. This may be fortuitous, but there are several possible reasons why male dancers might be more susceptible. Boys often take up ballet later than girls-as late as fifteen to seventeen years of age in our male patients, who nevertheless were all in top companies. The man's legs have often to carry his partner's weight as well as his own. The man's position on "half-points" is reputed-for what this is worth-to throw more strain on the calf than the stance of the danseuse on her "points." The man's leg is heavier and consequently its inertia is greater. But possibly the most important source of trouble is the man's great and magnificent leaps; it was the take-off in these that gave pain.

The site-The lesion was always at about the middle of the tibial crest. Only one leg was affected; some of the dancers considered it the dominant one.

The symptom common to all the men was gradually increasing pain, confined or almost confined to the take-off in jumps and never present during rest. The character of the danseuse's pain is unknown. No injury was recollected except in Case 2.

The signs-All the patients presented tenderness and a palpable lump, but the pain was always noticed first.

Radiological appearances-The most obvious thing was a horizontal fissure extending into the cortex of the tibial crest, which was itself thickened by subperiosteal new bone with a slightly irregular surface. The fissure lay mainly, but not wholly, in the new bone, and seemed to extend only a short way into the original cortex. Sometimes it showed a finely pencilled outline of increased density. The changes were best seen in a lateral view; but they were also discernible in the antero-posterior view, in which the swelling might be mistaken for part of a well formed tibial crest, a supposition disproved by symmetrical radiography of both legs. Pathological examinations-Biopsy in two cases revealed no evidence of general disease but a complete absence of callus in the defects.

THE NATURE OF THE DEFECT

The radiological picture of the fissure, with the adjacent hyperostosis, is very reminiscent of some examples of Looser's umbauzonen of the osteomalacias, in which a well outlined fissure with pouting mouth may partly penetrate a long bone, often on its concavity. Similar looking defects occur in Paget's disease, but on the convexities (Fig. 17). The term pseudofracture has been applied to all these seeming infractions (incomplete fractures) in pathological bone, but has not yet been accurately defined. The histological appearances in our two cases subjected to biopsy exclude the possibility of general bone disease.

More rarely, the same radiological appearance of fissure and hyperostosis is found in incomplete fatigue fractures of the tibia (Roberts and Vogt 1939, Hartley 1942, 1943). The occupational incidence in our patients, taken with their good health, points insistently to fatigue or stress as the cause of the defect, and we conclude that it is a fatigue fracture-or more precisely a fatigue infraction, because it involves only part of the diameter of the bone.

Most fatigue or stress fractures of the tibia happen in the upper third. Here they are almost confined to children and adolescents, and, if incomplete, present the defect posteriorly. Fatigue fractures do however exceptionally happen at the middle of the tibia.

The level of a fatigue fracture in a bone, and the aspect on which it starts, must depend among other things upon the sites of greatest stress-not only the stresses of weight bearing, 
but those of movement. A bending force applied to a rod or tube must produce distraction stresses on one aspect and compression stresses on the other. It may be that distraction is more important than compression in starting a fatigue fracture and therefore in determining the orientation of an infraction. Consequently it would be understandable that a ballet dancer, who performs almost acrobatic movements, should crack the bone at a different level and on a different aspect from, say, a boy in a naval training establishment, who always moves at the double.

The failure of these infractions in normal bone to display the abundant callus and ready union of ordinary fatigue fractures may perhaps be attributed to distracting forces that continue if the provocative movement is persisted in. Probably more important is the virtual absence of play between the surfaces of an infraction. Completion of the fracture leads to ready union (Hartley 1942). A parallel may be drawn by the infractions in Paget's disease. Situated on the convexity of a bowed bone, they are subjected to a distracting force, and, being incomplete, they are protected from movement. If the fracture is completed they readily heal with the abundant callus so characteristic of Paget's disease.

\section{DIAGNOSIS}

What has been said of this lesion, and

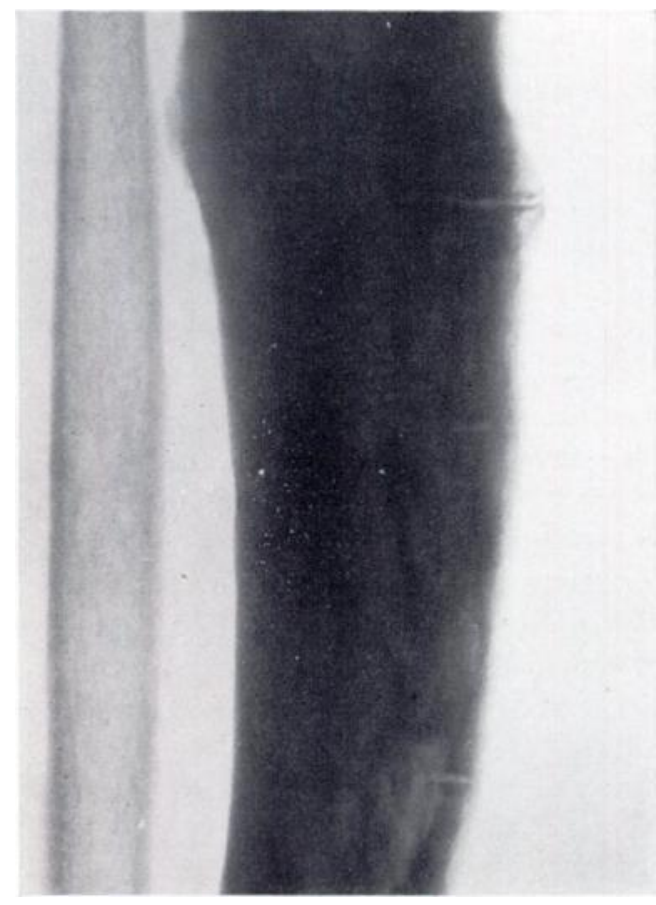

FIG. 17

Tibia in Paget's disease showing characteristic infractions on the convexity from bending stress in a curved structure of poor comps ition. particularly the disaster of Case 5 (whatever its true nature), confirms the importance of meticulous clinical and radiological examination. In doubtful cases multiple radiographs are needed with a marker at the site of tenderness, and the films should be scrutinised through a magnifying glass. The minute changes could easily be missed by a competent and careful clinician.

The clinical resemblance of osteoid osteoma and the radiological resemblance of infraction in bone diseases, such as osteomalacia and osteogenesis imperfecta, must be borne in mind.

\section{TREATMENT AND PROGNOSIS}

Though four patients have improved with rest, with or without biopsy, and have returned successfully to their strenuous occupation without prolonged immobilisation, the cures have not all been complete in the sense that every patient can use his full powers in leaping without a reminder of the lesion and that no evidence of the fissure is to be found in radiographs. A proper assessment will be possible only with the elapse of more time and the study of more cases.

When the diagnosis seems reasonably certain the best treatment may be immobilisation in a long walking plaster incorporating the knee and foot.

When the diagnosis is in doubt it may perhaps be better sometimes to remove a block of bone containing the fissure and fill the gap with an inlay graft.

At present it is impossible to say when work can safely be resumed. To await radiographic restitution may be to postpone dancing indefinitely; some risk may have to be taken. Attention to tenderness and to graduation of work are perhaps the best safeguards.

VOL. 38 B, NO. 1, FEBRUARY 1956 


\section{SUMMARY}

1. A defect of the middle of one tibial crest is described in young healthy ballet dancers.

2. The clinical and radiological characteristics have been studied in four cases, and the histological appearances in two.

3. The defect is concluded to be an incomplete fatigue fracture-a fatigue infraction.

4. A fifth, uncertain, case has been added tentatively, as presenting a possible serious complication, namely acute fracture from muscle action.

5. The diagnosis, treatment and prognosis are mentioned, with emphasis on the importance of adequate clinical and radiological examination in cases of obscure mid-tibial pain, tenderness or swelling.

I have to thank Dr E. F. Scowen for referring most of these patients, Dr H. A. Sissons for the histological investigations, and Dr Campbell Golding for some of the radiography; from all these I have had valuable help and advice, as also from Dame Ninette de Valois. I am indebted to Mr D. V. Webb for photomicrography, and to Mr R. J. Whitley and Mr H. G. Berkshire for other photographic work.

\section{REFERENCES}

Hartley, J. Blair (1942): Fatigue Fracture of the Tibia. British Journal of Surgery, $30,9$.

HARTLEY, J. Blair (1943): “ Stress ” or “ Fatigue ” Fractures of Bone. British Journal of Radiology, N.S. $16,255$. RoberTs, S. M., and Vogt, E. C. (1939): Pseudofracture of the Tibia. Journal of Bone and Joint Surgery, $21,891$. 